\title{
Bending resistance of PVA fiber reinforced cementitious composites containing nano-SiO
}

https://doi.org/10.1515/ntrev-2019-0060

Received Dec 01, 2019; accepted Dec 17, 2019

\begin{abstract}
In this study, the effects of polyvinyl alcohol (PVA) fiber content and nano-SiO ${ }_{2}$ (NS) on bending resistance of cementitious composites were investigated including bending strength and toughness. PVA fiber contents from $0.6 \%$ to $1.5 \%$ were added in the composites. The NS contents was $0 \%$ and $2 \%$ by mass. The water to binder ratio $(\mathrm{w} / \mathrm{b})$ was 0.38 for all composites. The specimens were cured for 28 days under $20^{\circ} \mathrm{C}$ and relative humidity of 95\% before bending test. The results show that the bending strength was improved with PVA fiber content increasing and the maximum bending strength was obtained at PVA fiber content of $1.5 \%$. Although PVA fiber increased bending resistance regardless of NS addition, the optimal content was $1.2 \%$. When the fiber content was less than $1.2 \%$, the bending resistance of cementitious composites increased with fiber content. However, the toughness began to decrease as PVA fiber content increased from $1.2 \%$ to $1.5 \% .2 \%$ NS addition decreased both bending strength and toughness due to the fact that NS was prone to selfdesiccation and flock together, resulting in micro crack and strength loss.
\end{abstract}

Keywords: PVA fiber reinforced composite, nano-SiO ${ }_{2}$, bending test, toughness

\section{Introduction}

The biggest challenges of traditional cementitious compositesare low ductility and high fracture risk which have brought many limitations in their structural applica-

\footnotetext{
*Corresponding Author: Yifeng Ling: National Concrete Pavement Technology Center, Institute for Transportation, IA 50014, United States of America; Email: yling@iastate.edu Peng Zhang, Juan Wang: School of Water Conservancy Engineering, Zhengzhou University, Zhengzhou 450001, China Yan Shi: Changjiang River Scientific Research Institute of Changjiang Water Resources Commission, Wuhan 430010, Hubei, China
}

əopen Access. ๑ 2019 P. Zhang et al., published by De Gruyter. (cc) BY License tions [1, 2]. A variety of researches have been carried outto investigate the performance and advantages of fiber reinforced compositesin the last few decades. The commonly used fibers in cementitious composites include steel, glass, polyethylene, polypropylene, polyvinyl alcohol, polyester, aramid and natural plant [3-10], among which polyvinyl alcohol (PVA) fiberis one of the most popular and widely studied fibers in research to improve ductility and reduce the propagation rate of cracks [11]. The mechanism of PVA fiber is mainly to reduce stress concentrations on internal defects of cementitious composites leading to an increase in toughness and ductility [12]. Yu et al. studied the tensile behavior of PVA reinforced concrete. Their concretes had enhanced tensile stress and strain capacities because PVA fiber increased toughness [13]. Cadoni et al. found that PVA fiber addition noticeably reduced fracture energy and improved tensile strength and tensile strain capacity [14] using a dynamic tensile test. Haskett et al. concluded that after adding PVA fibers, the crack amount in compression zone of concrete was effectively reduced [15]. Even after cracking, PVA fiber reinforced composites exhibited strain hardening behavior due to the bridging effect of fibers [16]. Ling et al. conducted an investigation on flexural bending behavior of PVA fiber reinforced cementitious composites. Their observation showed that bending strength and toughness were significantly increased by adding PVA fiber up to $1.5 \%$ volume content [17]. Many researchers have confirmed that fiber content greatly affects bending resistance of cementitious composite. Atahan et $a l$. addressed that fiber volume content between $0.5 \%$ and $2.0 \%$ considerably improved flexural behavior of cementitious composites [18]. High amount of PVA fiber increased bending resistanceand durability of composites [19, 20].

However, a large number of studies have pointed that PVA fibers can be easily pulled out under bending due to low bond strength between matrix and fibers which weakens its bridging effect. Especially for the cementitious composites containing fly ash, low reaction rate of fly ash hurt the interfacial bond strength between cementitious matrix and PVA fibers [21]. The failure mode of fibers under bending load consists of pullout with slight abrasion, surface abrasion and a partially peeled end [22]. Similar 
Table 1: Composition of cement and fly ash

\begin{tabular}{ccccccccc}
\hline Composition (\%) & $\mathrm{SiO}_{2}$ & $\mathrm{Al}_{2} \mathrm{O}_{3}$ & $\mathrm{Fe}_{2} \mathrm{O}_{3}$ & $\mathrm{CaO}$ & $\mathrm{MgO}$ & $\mathrm{Na}_{2} \mathrm{O}$ & $\mathrm{K}_{2} \mathrm{O}$ & $\mathrm{SO}_{3}$ \\
\hline Cement & 21.05 & 5.28 & 2.57 & 63.14 & 3.58 & 0.17 & 0.58 & 2.39 \\
Fly ash & 52.12 & 17.86 & 6.57 & 9.12 & 3.26 & 2.38 & 2.05 & 0.23 \\
\hline
\end{tabular}

Table 2: Physical properties of PVA fiber

\begin{tabular}{ccccccc}
\hline $\begin{array}{c}\text { Specific } \\
\text { gravity }\end{array}$ & $\begin{array}{c}\text { Dry fracture } \\
\text { elongation } \\
(\%)\end{array}$ & $\begin{array}{c}\text { Fiber length } \\
(\mathrm{mm})\end{array}$ & $\begin{array}{c}\text { Fiber diameter } \\
(\mu \mathrm{m})\end{array}$ & $\begin{array}{c}\text { Tensile } \\
\text { strength } \\
(\mathrm{MPa})\end{array}$ & $\begin{array}{c}\text { Water } \\
\text { absorption } \\
(\%)\end{array}$ & $\begin{array}{c}\text { Melting point } \\
\left({ }^{\circ} \mathrm{C}\right)\end{array}$ \\
\hline 1.32 & 15 & 9 & 20 & 1400 & $<1$ & 220 \\
\hline
\end{tabular}

occurrence of pullout PVA fibers was also found in fly ash geopolymer composites [23]. Such reduction in bond strength is also related to the increased porosity of composites induced by PVA fibers [23, 24]. Therefore, it is critical to find a solution for reducing porosity and improving bond strength between cementitious matrix and PVA fibers in order to enhance the bridging effect of PVA fibers in cementitious composite.

The use of nanoparticles in the concrete has been increasing in decades. Previous study results indicated that nano- $\mathrm{SiO}_{2}$ (NS) could significantly enhance strength and durability of concrete as an additive as a cementitious material due to their effects on hydration acceleration and microstructure evolution [25-27]. This improvement in concrete performance is not only attributed to its filler effect and its pozzolanic reaction, but also related to its larger surface area, which speeds up the rate of cement hydration and pozzolanic reactions [28]. Gonzalez et al. added NS to increase the compressive strength and durability of concrete [29]. A study from Zhang et al. found that $2 \%$ nanoparticles in cementitious composite noticeably promoted compressive and bending strength [30] which was associated with the filling effectin voids and between unreacted particles to decrease total porosity of the system [31, 32]. Sikora et al. used nano- $\mathrm{Fe}_{3} \mathrm{O}_{4}$ in cementitious composites to greatly improve the microstructure of cementitious composites was and decrease the porosity, thus increasing density of the composites [33]. Li et al. put forward that the addition of nanoparticles significantly promoted bending resistance, microstructure and ductility of cementitious composites [34]. In addition, NS has been found that it can substantially enhance the bond strength in cementitious composites due to the nanometer effects [3538]. Therefore, understanding the effects of nanoparticles on bending resistance of PVA fiber reinforced composite is important to evaluate bond strength between cementitious matrix and PVA fibers. Relative studies on the bend- ing resistance of such composites containing NS are very limited.

Although many researches have been conducted on the bending resistance of PVA fiber reinforced cementitious composites or NS reinforced cementitious composites, the studies on the bending resistance of cementitious composites simultaneously added with PVA fiber and NS were still in lack. In present study, NS were adopted to manufacture the PVA reinforced cementitious composites. A bending test was performed on the composites containing NS with various PVA fiber contents. The effects of varied PVA fiber contents and NS addition on bending properties of cementitious composites were investigated. The recommended dosages of PVA fiber and NS particles in cementitious composite were also provided based on the experimental results.

\section{Experiments}

\subsection{Materials}

A Portland cement with 3.13 specific gravity and 3266 $\mathrm{cm}^{2} / \mathrm{g}$ specific surface was specified as P.042.5 [39]. The low calcium fly ash complied as first grade in GB/T 15962017 [40] with 2.13 specific gravity and $2464 \mathrm{~cm}^{2} / \mathrm{g}$ specific surface. Table 1 presents the chemical composition of cementitious materials (cement and fly ash). Table 2 lists the physical properties of PVA fiber. $\mathrm{Nano}^{-\mathrm{SiO}_{2}}$ (NS) from Hangzhou Wanjing New Material Co. LTD were employed as nanoparticles in this study, and their properties are shown in Table 3. The workability of fresh mixtures was adjusted using ahigh range water reducing admixture with its properties provided in Table 4. The sand had grain size within $212-380 \mu \mathrm{m}$. 
Table 3: Basic properties of nanoparticles

\begin{tabular}{cccccc}
\hline Nano particles & $\begin{array}{c}\text { Average size } \\
(\mathrm{nm})\end{array}$ & $\begin{array}{c}\text { Content } \\
(\%)\end{array}$ & Specific surface $\left(\mathrm{m}^{2} / \mathrm{g}\right)$ & $\begin{array}{c}\text { Bulk density } \\
\left(\mathrm{g} / \mathrm{cm}^{3}\right)\end{array}$ & $\mathrm{PH}$ \\
\hline $\mathrm{SiO}_{2}$ & 30 & 99.5 & 200 & 0.055 & 6 \\
\hline
\end{tabular}

Table 4: High range water reducing admixture properties

\begin{tabular}{ccccc}
\hline Specific gravity & Alkali Content (\%) & PH & $\begin{array}{c}\text { Chloride ion content } \\
(\%)\end{array}$ & Effective rate (\%) \\
\hline 1.06 & 1.2 & 4.62 & 0.078 & 22.0 \\
\hline
\end{tabular}

Table 5: Mixture proportions of composites

\begin{tabular}{cccccccc}
\hline Mixture & $\begin{array}{c}\text { Cement } \\
\left(\mathrm{kg} / \mathrm{m}^{3}\right)\end{array}$ & $\begin{array}{c}\text { Fly ash } \\
\left(\mathrm{kg} / \mathrm{m}^{3}\right)\end{array}$ & $\begin{array}{c}\text { NS } \\
\left(\mathrm{kg} / \mathrm{m}^{3}\right)\end{array}$ & $\begin{array}{c}\text { PVA fiber } \\
(\%)\end{array}$ & $\begin{array}{c}\text { Sand } \\
\left(\mathrm{kg} / \mathrm{m}^{3}\right)\end{array}$ & $\begin{array}{c}\text { Water } \\
\left(\mathrm{kg} / \mathrm{m}^{3}\right)\end{array}$ & $\begin{array}{c}\text { High range water reducing } \\
\text { admixture }\left(\mathrm{kg} / \mathrm{m}^{3}\right)\end{array}$ \\
\hline P0.6 & 650 & 350 & 0 & 0.6 & 500 & 380 & 3 \\
P0.9 & 650 & 350 & 0 & 0.9 & 500 & 380 & 3 \\
P1.2 & 650 & 350 & 0 & 1.2 & 500 & 380 & 3 \\
P1.5 & 650 & 350 & 0 & 1.5 & 500 & 380 & 3 \\
P0.6-N & 630 & 350 & 20 & 0.6 & 500 & 380 & 3 \\
P0.9-N & 630 & 350 & 20 & 0.9 & 500 & 380 & 3 \\
P1.2-N & 630 & 350 & 20 & 1.2 & 500 & 380 & 3 \\
P1.5-N & 630 & 350 & 20 & 1.5 & 500 & 380 & \\
\hline
\end{tabular}

Note: All mixtures are named as P or P-N, where P is PVA fiber content and N is NS.

\subsection{Mixture proportions}

Based on the study from Yew et al, the recommended dosage of PVA fiber in concrete materials is from $0.1 \%$ to $3.0 \%$ [30]. Therefore, in this study, Six volume contents of PVA fiber $(0.6 \%, 0.9 \%, 1.2 \%$ and $1.5 \%$ of composite) were respectively added to the cementitious composites with $0 \%$ and $2 \%$ NS by mass of binder (cement, fly ash and NS). In total, 8 cementitious composite mixtures were prepared with $0.38 \mathrm{w} / \mathrm{b}$ and 2 binder to sand ratio (b/s).Mixture proportions are presented in Table 5.

\subsection{Experimental methods}

\subsubsection{Mixing}

A laboratory Hobart mixer was used to mix the fresh cementitious composites in accordance with ASTM C305 [41]. A dry mixing with silica sand, cement, fly ash and nanoparticles was first proceeded for $2 \mathrm{~min}$. Secondly, one in three water with half high range water reducing admixture was introduced and agitated for 60 seconds. Next, another third of water along with the rest high range water reducing admixture was added and mixed for 60 seconds. Then last third of water was added and stirred for 60 seconds. At last, PVA fibers were evenly quadripartite and respectively mixed with the mixture for $2.5 \mathrm{~min}$. Before engineering property tests, all cast specimens were demolded in 24 hours and have 28 -day curing of $20^{\circ} \mathrm{C}$ and $95 \%$ relative humidity.

\subsubsection{Bending test}

A four-point bending test was carried out on a beam specimen to evaluate bending behavior of the cementitious composite as illustrated in Figures 1 and 2. For each mix, three beams with a dimension of $400 \mathrm{~mm} \times 100 \mathrm{~mm} \times 100 \mathrm{~mm}$ were cast and the reported result was the average of three specimens. To perform the test, the tested beam was simply supported with a support span of $300 \mathrm{~mm}$ as illustrated in Figure 1 . Two bending loads were applied symmetrically at $100 \mathrm{~mm}$ from the supports using a loading machine. The loading span was one-third of the support span. One LVDT was installed on the side of beam to monitor the mid-span deflections of the beam as seen in Figure 1. In accordance with JG/T 472-2015 [42], the loads were applied at a rate of $30 \mathrm{~N} / \mathrm{s}$ until specimen failed. The bending stress in the 


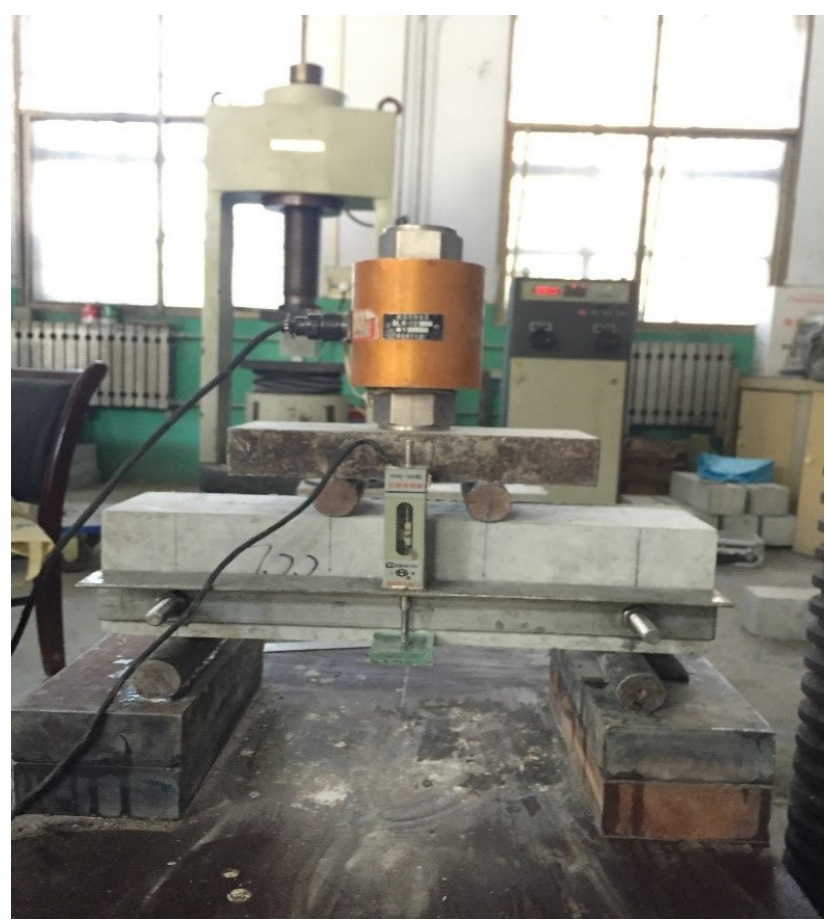

Figure 1: Data collection of bending test

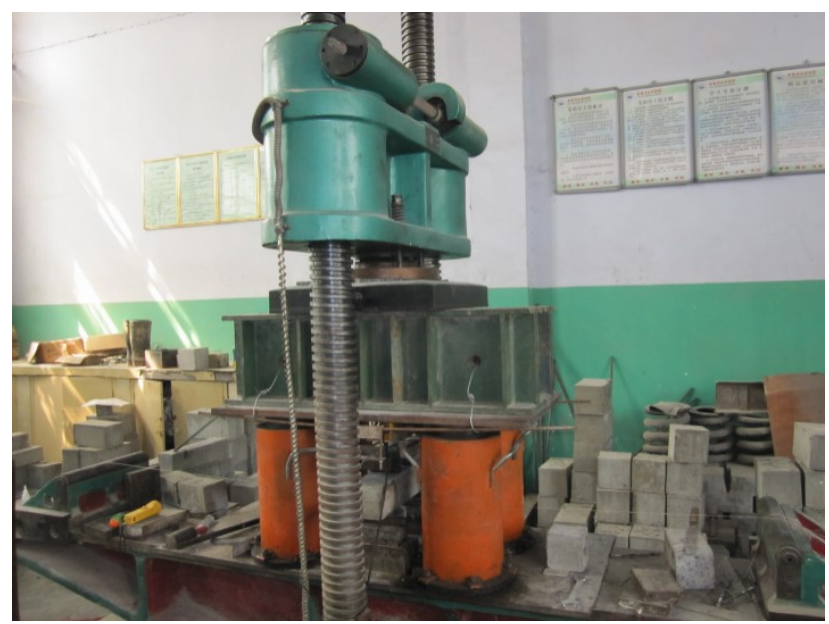

Figure 2: Testing apparatus of bending test

tested slab was calculated according to Eq. (1):

$$
f=\frac{F L}{b d^{2}}
$$

Where $f$ is bending stress; $F$ is the load; $L$ is the length of the support span; $b$ is the width of slab and $d$ is thickness of slab.

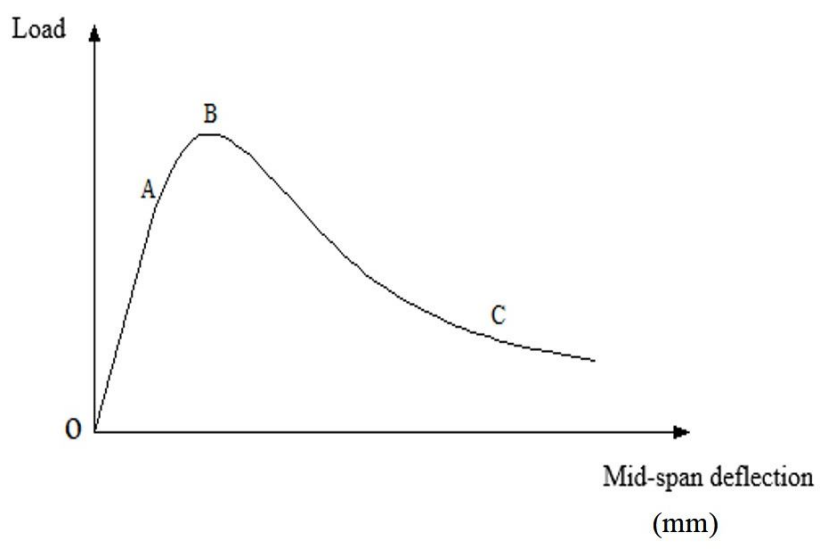

Figure 3: A typical curve of load vs. mid-span deflection

\subsubsection{Evaluation of bending resistance}

A typical load vs. mid-span deflection plot was presented in Figure 3. The entire fracture process can be separated to three phases: $\mathrm{OA}, \mathrm{AB}$ and $\mathrm{BC}$. In OA, matrix and PVA fiber are bearing load together. The specimen behaves elastically. Deflection is changing linearly with load. As load increases, the deformation of tensile zone of the cement matrix composites will reach the material's initial crack strain, and cracks begin to appear. At point A, traditional cement composites fracture immediately, while PVA fiber reinforced composites exhibit deflection hardening behavior, i.e. load keeps going up with deflection increasing until peak load (point $B$ ), which is due to bridging effect of PVA fibers. In $\mathrm{AB}$, cracks in specimen propagate stably. The relationship between load and deflection is non-linear, and the specimen is elastic-plastically deforming. Point $B$ is the critical point of crack instable propagation, which reaches the ultimate load of the specimen. In BC, with PVA fibers fractured or pulling out, the specimen eventually fractures at point $\mathrm{C}$.

In JG/T 472-2015 [42], bending resistance parameters are presented in a typical load-deflection (F- $\delta$ ) curve (Figure 4). $\delta_{p}$ is the deflection at peak load and $\delta_{k}$ is the given deflection.

Initial flexural toughness ratio $\left(R_{e, p}\right)$ and flexural toughness ratio $\left(R_{e, k}\right)$ were used to characterize the bending resistance before peak load and the bending resistance after peak load respectively. $R_{e, p}$ can be determined by Eq. (2) and Eq. (3)

$$
\begin{gathered}
R_{e, p}=f_{e, p} / f_{f t m} \\
f_{e, p}=\frac{\Omega_{p} L}{b h^{2} \delta_{p}}
\end{gathered}
$$




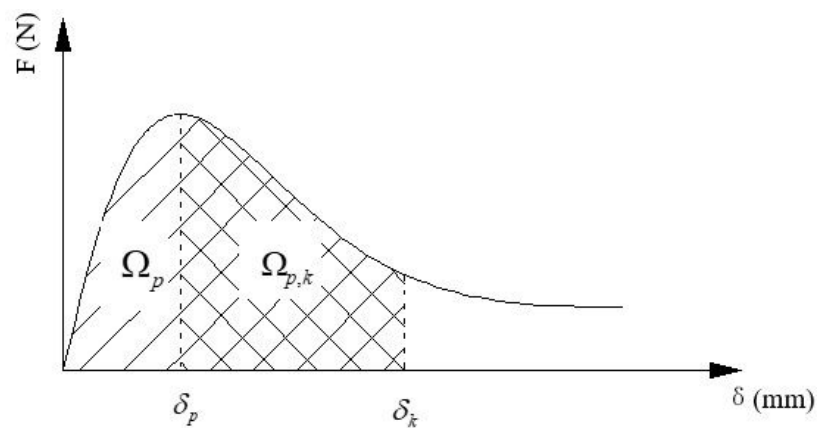

Figure 4: Bending resistance parameter calculation

Where $f_{e, p}(\mathrm{MPa})$ is equivalent bending strength at peak load; $b(\mathrm{~mm})$ is width of beam; $h(\mathrm{~mm})$ is thickness of beam; $L(\mathrm{~mm})$ is support span; $\delta_{p}(\mathrm{~mm})$ is deflection of peak load; $\Omega_{p}(\mathrm{~N} \cdot \mathrm{mm})$ is area under load-deflection curve before peak load; $f_{f t m}(\mathrm{MPa})$ is bending strength of specimen.

While $R_{e, k}$ is expressed as Eq. (4)-Eq. (6)

$$
\begin{gathered}
R_{e, k}=f_{e, k} / f_{f t m} \\
f_{e, k}=\frac{\Omega_{p, k} L}{b h^{2} \delta_{p, k}} \\
\delta_{p, k}=\delta_{k}-\delta_{p}
\end{gathered}
$$

Where $\delta_{k}(\mathrm{~mm})$ is the given deflection $L / \mathrm{k}, \mathrm{k}=500,300 \mathrm{~mm}$; $f_{e, k}(\mathrm{MPa})$ is equivalent bending strength at deflection of $\delta_{k} ; \delta_{p, k}(\mathrm{~mm})$ is the increment from $\delta_{p}$ to $\delta_{k} ; \Omega_{p, k}(\mathrm{~N} \cdot \mathrm{mm})$ is the area under load-deflection curve from $\delta_{p}$ to $\delta_{k}$. The average of three duplicates was reported in this paper.

\section{Results and discussion}

\subsection{Bending behavior}

Figure 5 presents the relationships of load and mid-span deflection for composites with different PVA contents. It implies that irrespective of NS addition, a significant increment in ductility and toughness (area under curve) was achieved by increasing PVA content. This tendency is associated with that PVA displayed bridging effect by taking partial load on composite matrix which restrained crack development and sudden failure of specimen [43]. PVA content did not impact bending strength very much.

Figure 6 depicts the load vs. mid-span deflection for the NS composites with different PVA contents. Similar as those composites without NS, the ductility and toughness

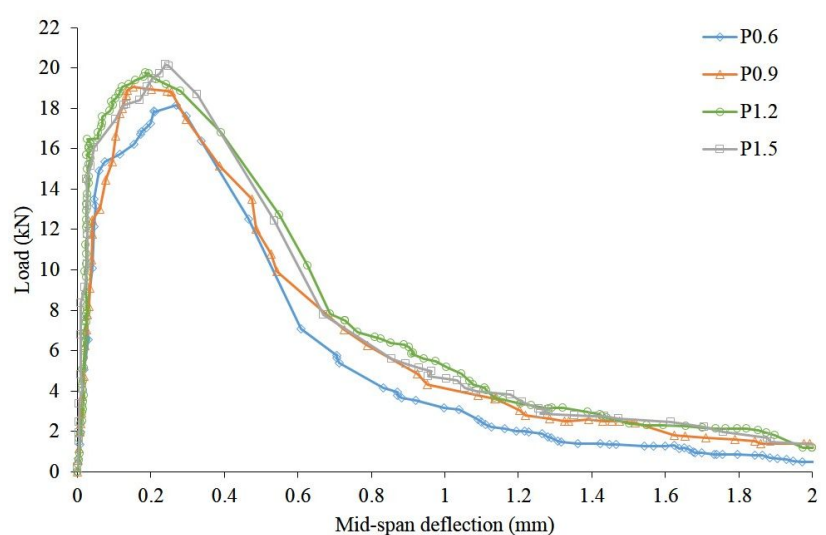

Figure 5: Load vs. mid-span deflection for composites with different PVA contents

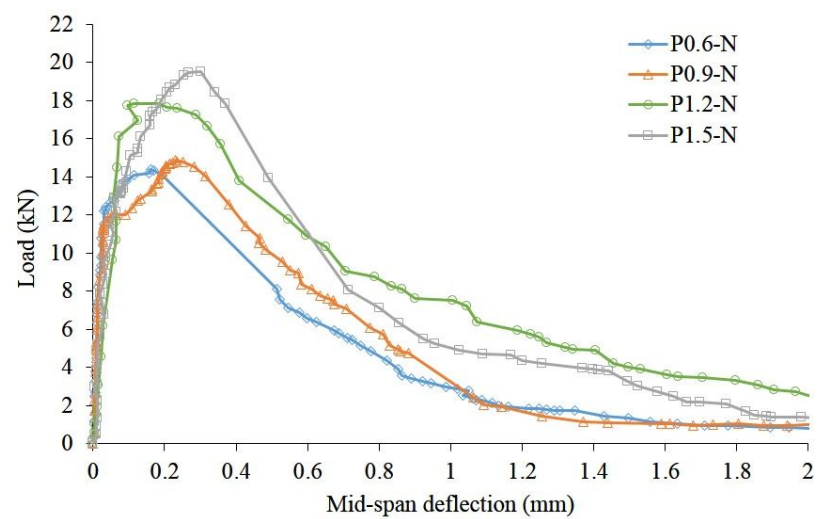

Figure 6: Load vs. mid-span deflection for NS composites with different PVA contents

of the composites containing NS also greatly increased with PVA content increasing from 0\%-1.5\%. Comparing Figure 5 and Figure 6, NS addition conversely reduced flexural leak load of composites. This is because too much NS was prone to self-desiccation, leading to micro crack in composite [44].

In summary, PVA fibers play a significant role in bridging microcracks when applied to cementitious composites, and the bond strength between the cementitious matrix and PVA fibers has a certain anti-cracking effect. Besides, the disordered PVA fibers distributing in three dimensions could form a structural support inside the composites which improved bending strength. Under the loads, microcracks appeared with high stress concentration on crack tip. When the crack tip reached PVA fibers, PVA fibers inhibited the propagation of the cracks, since PVA fiber had much larger strengthand size than the matrix and the crack tip respectively [45]. Consequently, with an appropriate content, the addition of PVA fibers remarkably improve the flexural properties of the composites containing NS. 


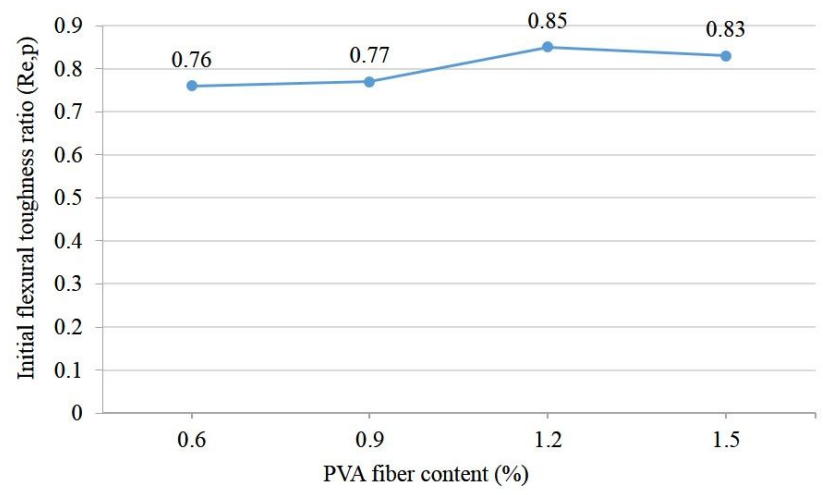

Figure 7: Initial flexural toughness ratio $\left(R_{e, p}\right)$ of composites with different PVA fiber contents

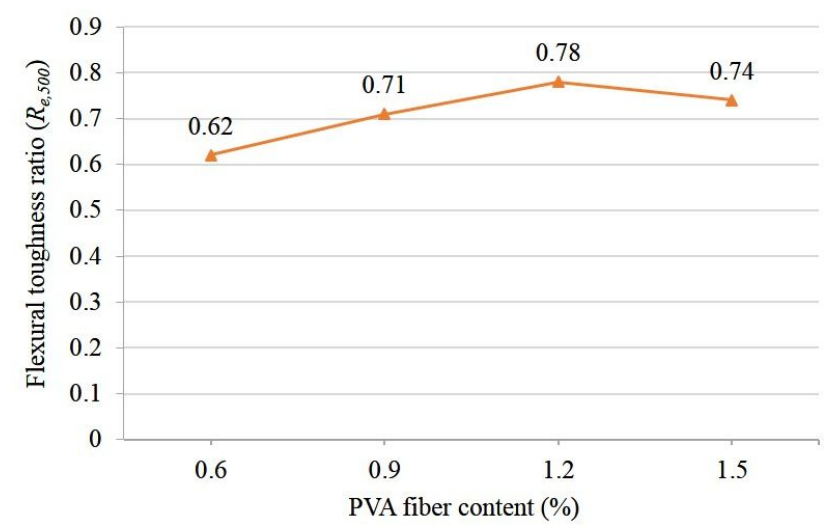

Figure 8: Flexural toughness ratio $\left(R_{e, 500}\right)$ of composites with different PVA fiber contents

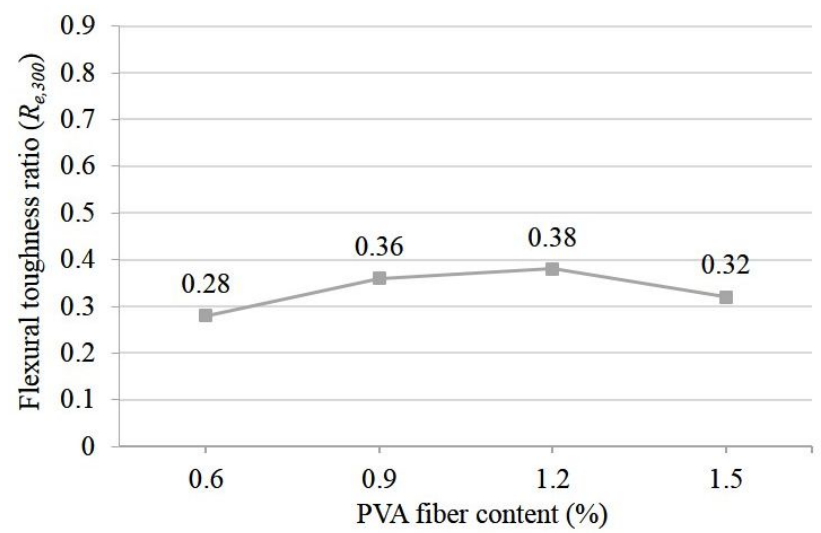

Figure 9: Flexural toughness ratio $\left(R_{e, 300}\right)$ of composites with different PVA fiber contents

However, if its content was too high, PVA fibers themselves increased the amount of microcracks and cause dun expected defects inside the composites. Therefore, PVA fiber content more than $2 \%$ decreased bending strength and resistance of the cementitious composites containing NS.

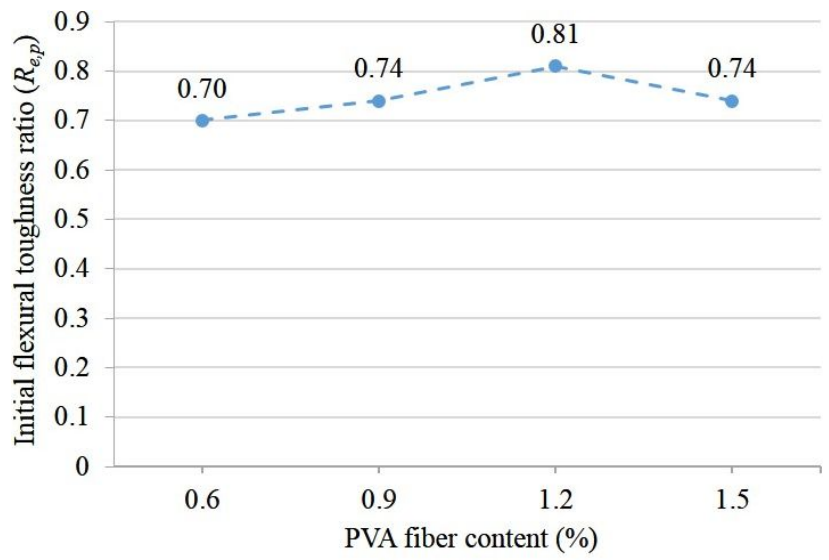

Figure 10: Initial flexural toughness ratio $\left(R_{e, p}\right)$ of NS composites with different PVA fiber contents

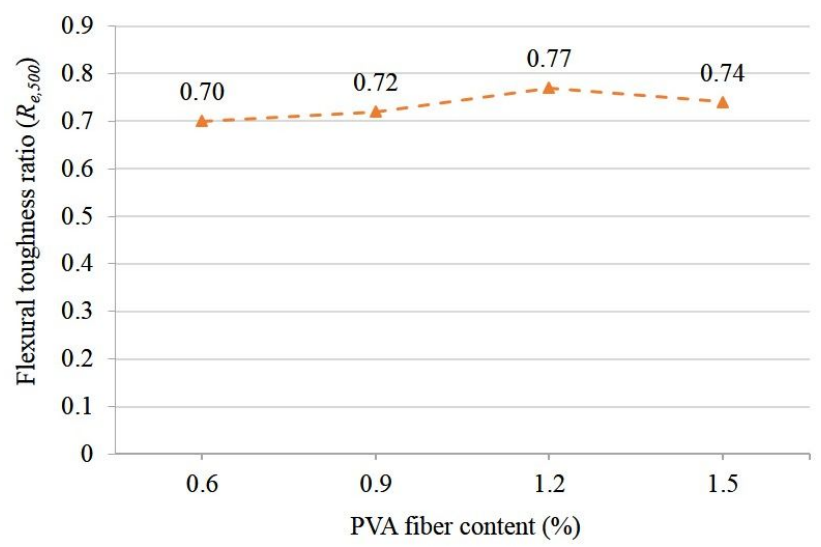

Figure 11: Flexural toughness ratio $\left(R_{e, 500}\right)$ of NS composites with different PVA fiber contents

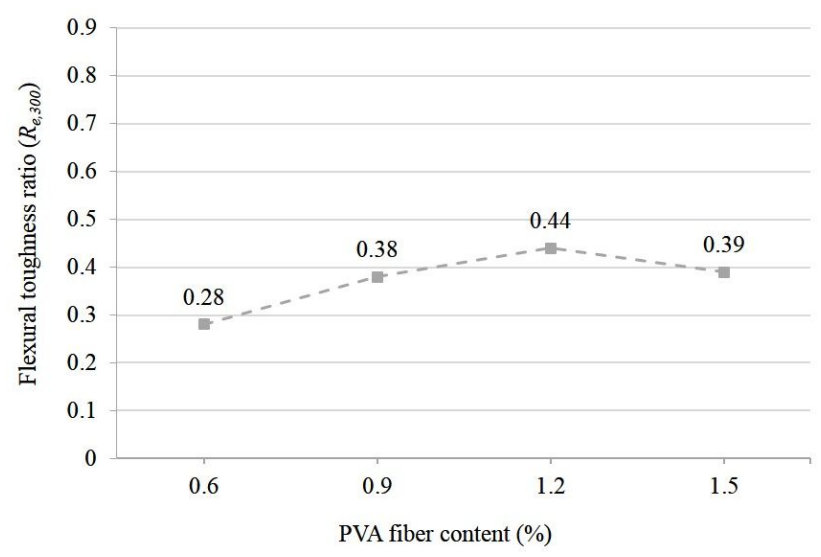

Figure 12: Flexural toughness ratio $\left(R_{e, 300}\right)$ of NS composites with different PVA fiber contents

\subsection{Bending resistance}

The flexural toughness ratios along with PVA fiber contents are shown from Figures 7-12 for both composites with- 
Table 6: Summary of bending parameters

\begin{tabular}{ccccccc}
\hline Mix & $f_{e, p}(\mathrm{MPa})$ & $R_{e, p}$ & $f_{e, 500}(\mathrm{MPa})$ & $R_{e, 500}$ & $f_{e, 300}(\mathrm{MPa})$ & $R_{e, 300}$ \\
\hline P0.6 & 4.16 & 0.76 & 3.41 & 0.62 & 1.56 & 0.28 \\
P0.9 & 4.29 & 0.77 & 3.93 & 0.71 & 1.97 & 0.36 \\
P1.2 & 4.96 & 0.85 & 4.54 & 0.78 & 2.21 & 0.38 \\
P1.5 & 5.28 & 0.83 & 4.74 & 0.74 & 2.02 & 0.32 \\
P0.6-N & 3.18 & 0.70 & 3.14 & 0.70 & 1.27 & 0.28 \\
P0.9-N & 3.46 & 0.74 & 3.35 & 0.72 & 1.76 & 0.38 \\
P1.2-N & 3.99 & 0.81 & 3.79 & 0.77 & 2.16 & 0.44 \\
P1.5-N & 4.48 & 0.74 & 4.48 & 0.74 & 2.33 & 0.39 \\
\hline
\end{tabular}

out and with NS. As shown in Figures 7-9, without NS addition, all flexural toughness ratios $\left(R_{e, p}, R_{e, 500}\right.$, and $R_{e, 300}$ ) were significantly increased when PVA content altered from $0 \%$ to $1.2 \%$, while they declined at $1.5 \%$ PVA. This trend indicates that PVA fiber could considerably improve bending resistance and its improvement on bending resistance after peak load was much higher than that before peak load. Coincident findings were obtained on the cementitious composites with NS. This is associated with the fact that the bond between PVA and composites was taking partial load until PVA was fractured or pulled out from the matrix. Moreover, the bridging effect of PVA fibers inhibited the crack propagation which reduced the stress concentration on tip of crack [43]. Comparing with $0.6 \%$, $1.2 \%$ PVA addition increased $R_{e, p}, R_{e, 500}$, and $R_{e, 300}$ by $11.8 \%, 25.8 \%$ and $35.7 \%$ respectively for the composites without NS, and $15.7 \%, 10.0 \%$ and $57.1 \%$ respectively for the composites with NS. However, for the excessive PVA fiber addition (1.5\%), the flexural toughness ratios were decreased due to non-uniform distribution of PVA fibers caused in matrix [23, 46]. Such phenomenon is related to the agglomeration of PVA fibers leading to an increase in porosity which weakened the bond strength between PVA fibers and cementitious matrix [46]. It should be noted that the addition of NS did not noticeably increase the flexural toughness ratios. Its reason needs further investigation.

The bending resistance parameters are summarized in Table 6. It can be concluded that the bending strengths $\left(f_{e, p}, f_{e, 500}\right.$ and $\left.f_{e, 300}\right)$ were improved by adding PVA fibers up to $1.5 \%$, regardless of NS. This improvement in bending strength was due to the linkage created by PVA which enhanced the strength in tensile zone [47]. Overall, in comparison of $0.6 \%, 1.5 \%$ PVA addition increased $f_{e, p}, f_{e, 500}$, and $f_{e, 300}$ by $26.9 \%, 39.0 \%$ and $29.5 \%$ respectively for the composites without NS, and $40.9 \%, 42.7 \%$ and $83.5 \%$ respectively for the composites with NS. The optimum PVA fiber volume content for toughness was $1.2 \%$. However, $2 \%$ NS addition slightly reduced bending strengths. Ide- ally, the particle size of NS is smaller than cement, which can effectively improve the interfacial structure properties. NS can also react with $\mathrm{Ca}(\mathrm{OH})_{2}$ to form $\mathrm{CaSiO}_{3}$, which has filling action and improve the microstructure inside the composites. Consequently, the bonding force between PVA fibers and the matrix should be strengthened [45]. In fact, the excessive NS tends to flock together and reduces strength because of large molecular force [48] implying that $2 \%$ was beyond the optimum content for NS addition in cementitious composites.

\section{Conclusions}

In this paper, the bending resistance of PVA fiber reinforced cementitious composites with NS addition was systematically investigated. The effects of PVA fiber content and NS addition on bending resistance of the cementitious composites were initially evaluated. The following conclusions were drawn according to experimental results:

1. The bending strength was considerably enhanced with PVA fiber content increasing $(0.6-1.5 \%$ by volume) and the maximum bending strength was obtained at PVA fiber content of $1.5 \%$.

2. Although PVA fiber significantly improved bending resistance regardless of NS addition, there was an optimum PVA content of $1.2 \%$ by volume to achieve the maximum toughness and ductility. When the fiber content was less than $1.2 \%$, the bending resistance of cementitious composites increased with fiber content. However, the toughness began to decrease as PVA fiber content increased from $1.2 \%$ to $1.5 \%$.

3. $2 \% \mathrm{NS}$ addition was too excessive to increase both bending strength and toughness because NS was prone to self-desiccation and flock together, leading to micro crack and strength loss in composite. An 
NS dosage lower than $2 \%$ was recommended to improve bending strength and toughness, as well as the bond strength between cementitious matrix and PVA fibers.

Acknowledgement: The authors would like to acknowledge the financial support received from National Natural Science Foundation of China (Grant No. 51678534), Program for Innovative Research Team (in Science and Technology) in University of Henan Province of China (Grant No. 20IRTSTHN009), CRSRI Open Research Program (Grant No. CKWV2018477/KY), and Open Projects Funds of Dike Safety and Disaster Prevention Engineering Technology Research Center of Chinese Ministry of Water Resources (Grant no. 2018006).

\section{References}

[1] Huang B., Li Q., Xu S., Zhou B., Tensile fatigue behavior of fiberreinforced cementitious material with high ductility: Experimental study and novel P-S-N model, Constr. Build. Mater., 2018, 178, 349-359.

[2] Yu K., Dai J., Lu Z., Christopher K., Leung M., Mechanical properties of engineered cementitious composites subjected to elevated temperatures, J. Mater. Civ. Eng., 2015, 27(10), 04014268.

[3] Caggiano A., Folino P., Lima C., Martinelli E., Pepe M., On the mechanical response of hybrid fiber reinforced concrete with recycled and industrial steel fibers, Constr. Build. Mater., 2017, 147, 286-295.

[4] Adam M., Said M., Mahmoud A., Shanour A., Analytical and experimental flexural behavior of concrete beams reinforced with glass fiber reinforced polymers bars, Constr. Build. Mater., 2015, 84, 354-366.

[5] Yamaguchi M., Murakami K., Takeda K., Mitsui Y., Blast resistance of polyethylene fiber reinforced concrete to contact detonation, J. Adv. Concr. Technol., 2011, 9(1), 63-71.

[6] Zhang P., Li Q., Effect of polypropylene fiber on durability of concrete composite containing fly ash and silica fume, Compos. Part B: Eng., 2013, 45, 1587-1594.

[7] Li D., Cao H., Ou J., Fracture behavior and damage evaluation of polyvinyl alcohol fiber concrete using acoustic emission technique, Mater. Design, 2012, 40, 205-211.

[8] Weng X., Study on anti-aging property of pavement modified polyester fiber reinforced concrete, J. Build. Mater., 2010, 13(6), 749-752.

[9] Zheng Y., Wu X., He G., Shang Q., Xu J., Sun Y., Mechanical properties of steel fiber-reinforced concrete by vibratory mixing technology, Adv. Civ. Eng., 2018, 9025715.

[10] Ferdiansyah T., Razak H.A., Mechanical properties of black sugar palm fiber-reinforced concrete, J. Reinf. Plast. Comp., 2011, 30(11), 994-1004.

[11] Kasagani H., Rao C.B.K., Effect of graded fibers on stress strain behaviour of glass fiber reinforced concrete in tension, Constr. Build. Mater., 2018, 183, 592-604.
[12] Irshidat M.R., Al-Shannaq A., Using textile reinforced mortar modified with carbon nano tubes to improve flexural performance of RC beams, Compos. Struct., 2018, 200, 127-134.

[13] Yu K., WangY., Yu J., Xu S., A strain-hardening cementitious composites with the tensile capacity up to $8 \%$, Constr. Build. Mater., 2017, 137, 410-419.

[14] Cadoni E., Meda A., Plizzari G.A.,Tensile behaviour of FRC under high strain-rate, Mater. Struct., 2009, 42, 1283-1294.

[15] Haskett M., Mohamed S.M., Oehlers D., Guest G., Pritchard T., Sedav V., Stapleton B., Deflection of GFRP and PVA fibre reinforced concrete beams, In Proceedings of the 6th International Conference on FRP Composites in Civil Engineering (CICE2012), Rome, Italy, 13-15 June 2012.

[16] Ling Y., Wang K., Li W., Shi G., Lu P., Effect of slag on the mechanical properties and bond strength of fly ash based engineered geopolymer composites, Compos. Part B: Eng., 2019, 164, 747 757.

[17] Ling Y., Zhang P., Wang J., Chen Y., Effect of PVA fiber on mechanical properties of cementitious composite with and without nano-SiO ${ }_{2}$, Constr. Build. Mater., 2019, 229, 117068.

[18] Atahan H.N., Pekmezci B.Y., Tuncel E.Y., Behavior of PVA fiberreinforced cementitious composites under static and impact flexural effects, J. Mater. Civ. Eng., 2013, 25(10), 1438-1445.

[19] Zanotti C., Borges P., Bhutta A., Banthia N., Bond strength between concrete substrate and metakaolin geopolymer repair mortar: Effect of curing regime and PVA fiber reinforcement, Cem. Concr. Compos., 2017, 80, 307-316.

[20] Wang J., Dai Q., Si R., Guo S., Investigation of properties and performances of Polyvinyl Alcohol (PVA) fiber-reinforced rubber concrete,Constr. Build. Mater., 2018, 193, 631-642.

[21] Ma H., Qian S., Zhang Z., Lin Z., Li V.C., Tailoring engineered cementitious composites with local ingredients, Constr. Build. Mater., 2015, 101, 584-595.

[22] Li H., Xu S., Leung C.K.Y., Tensile and flexural properties of ultrahigh toughness cementitious composite, J. Wuhan Univ.Technol. Mater. Sci. Ed., 2009, 24, 677-683.

[23] Topic J., Proseka Z., Indrova K., Plachy T., Nezerka V., Kopecky L., Tesarek P., Effect of PVA modification on the properties of cement composites, Acta Polytech., 2015, 55(1), 64-75.

[24] Ekaputri J.J., Limantono H., Triwulan T., Susanto T., Abdullah M.M.A.B., Effect of PVA fiber in increasing mechanical strength on paste containing glass powder, Key Eng. Mater., 2016, 673, 83-93.

[25] Khaloo A., Mobini M., Hosseini P. Influence of different types of nano- $\mathrm{SiO}_{2}$ particles on properties of high-performance concrete, Constr. Build. Mater., 2016, 113, 188-201.

[26] Zhang P., Wan J., Wang K., Li Q., Influence of nano-SiO2 on properties of fresh and hardened high performance concrete: A stateof-the-art review, Constr. Build. Mater., 2017, 148, 648-658.

[27] Bastos G., Patino-Barbeito F., Patino-Cambeiro F., Armesto J., Nano-inclusions applied in cement-matrix composites: a review, Materials, 2016, 9(12), 1015.

[28] Said A.M., Zeidan M.S., Bassuoni M.T., Tian Y., Properties of concrete incorporating nano-silica, Constr. Build. Mater., 2012, 36, 838-844.

[29] Gonzalez M., Tighe S., Hui K., Rahman S., Oliveira Lima A., Evaluation of freeze/thaw and scaling response of nano concrete for Portland cement concrete (PCC) pavements, Constr. Build. Mater., 2016, 120, 465-472. 
[30] Zhang L., Ma N., Wang Y., Han B., Cui X., Yu X., Ou J., Study on the reinforcing mechanisms of nanosilica to cement-based materials with theoretical calculation and experimental evidence, J. Compos. Mater., 2016, 50(29), 4135-4146.

[31] Givi A.N., Rashid S.A., Aziz F.N.A., Salleh M.A.M., Experimental investigation of the size effects of $\mathrm{SiO}_{2}$ nano-particles on the mechanical properties of binary blended concrete, Compos. Part B., 2010, 41(8), 673-677.

[32] Kazemi M.,Ghobadi M.,Mirzaie A., Cobalt ferrite nanoparticles $\left(\mathrm{CoFe}_{2} \mathrm{O}_{4} \mathrm{Mnps}\right)$ as catalyst and support: magnetically recoverable nanocatalysts in organic synthesis (nano-composites), Nanotechnol. Rev., 2018, 7, 43-68.

[33] Sikora P., Horszczaruk E., Cendrowski K., Mijowska E., Nanomodification to improve the ductility of cementitious composites, Nanoscale Res. Lett., 2015, 11, 1-9.

[34] Li Q.H., Gao X., Xu S.L., Multiple effects of nano-SiO2 and hybrid fibers on properties of high toughness fiber reinforced cementitious composites with high-volume fly ash, Cem. Concr. Compos., 2016, 72, 201-212.

[35] Li Z., Wang H., He S., Lu Y., Wang M., Investigations on the preparation and mechanical properties of the nano-alumina reinforced cement composite, Mater. Lett., 2006, 60, 356-359.

[36] Das S., Srivastava V., An overview of the synthesis of CuO-ZnO nanocomposite for environmental and other applications, Nanotechnol. Rev., 2018, 7, 267-282.

[37] Power A., Gorey B., Chandra S., Chapman J., Carbon nanomaterials and their application to electrochemical sensors: a review, Nanotechnol. Rev., 2018, 7, 19-41.

[38] Ossai C., Raghavan N., Nanostructure and nanomaterial characterization, growth mechanisms, and applications, Nanotechnol. Rev., 2018, 7, 209-231.
[39] GB 175-2007, Common Portland cement. Beijing: China Standards Press, 2007 (in Chinese).

[40] GB/T 1596-2017, Fly ash used for cement and concrete, Beijing: China Standards Press, 2017 (in Chinese).

[41] ASTM C305, Standard practice for mechanical mixing of hydraulic cement pastes and mortars of plastic consistency, ASTM International, PA, 2014.

[42] JG/T 472-2015, Steel fiber reinforced concrete, Building \& Construction Industry Standard, 2015 (in Chinese).

[43] Nematollahi B., Sanjayan J., Shaikh F.U.A., Comparative deflection hardening behavior of short fiber reinforced geopolymer composites, Constr. Build. Mater.,2014, 70, 54-64.

[44] Jo B.W., Kim C.H., Tae G., Park J.B., Characteristics of cement mortar with nano-SiO 2 particles, Constr. Build. Mater., 2007, 21(6), 1351-1355.

[45] Zhang P., Li Q., Wang J., Shi Y., Ling Y., Effect of PVA fiber on durability of cementitious composite containing nano-SiO ${ }_{2}$, Nanotechnol. Rev., 2019, 8, 116-127.

[46] Xu Z., Wang T., Wang W., Effect of PVA fiber content on creep property of fiber reinforced high-strength concrete columns, AIP Conference Proceedings, 2018, 1955, 020026.

[47] Yaowarat T., Horpibulsuk S., Arulrajah A., Mirzababaei M., Compressive and flexural strength of polyvinyl alcohol-modified pavement concrete using recycled concrete aggregates, J. Mater. Civ. Eng., 2018, 30(4).

[48] Abbasi S.M., Ahmadi G., KhalajG., Microstructure and mechanical properties of a metakaolinite-based geopolymer nanocomposite reinforced with carbon nanotubes, Ceram. Int., 2016, 42, 15171-15176. 